\title{
Interligação entre cardiologia intervencionista e cirurgia experimental
}

J.Eduardo Souza*

A aplicação do cateterismo, com finalidade terapêutica, no território vascular, data de 1964, quando Dotter e Judkins ${ }^{1}$ utilizaram um sistema coaxial de cateteres, para desobstruir artérias periféricas. Esta técnica foi chamada de angioplastia transluminal, mas não teve grande aceitação particularmente nos Estados Unidos, devido aos altos índices de complicações, em especial nas vias de acesso.

Gruentzig e colaboradore ${ }^{2}$ modificaram o sistema de múltiplos cateteres de Dotter e desenvolveu um cateter de dupla luz, na porção distal do qual, havia um balão distensível, feito de polivinil. Este balão quando insuflado, mostrou em modelos experimentais, exercer pressão circunferencial sobre a placa ateromatosa alargando a luz vascular.

As primeiras experiências de Gruentzig ${ }^{2}$, foram bem sucedidas no cão e em, 1976 este pesquisador miniaturizou os balões, com objetivo de realizar a angioplastia no território coronário, em animais de experimentação para depois, no ano seguinte aplica-lo em seres humanos na Universidade de Zurique, na Suíça.

Esta técnica granjeou então ampla aceitação e, em pacientes selecionados passou a ser aplicada como alternativa à intervenção cirúrgica, e representou um dos maiores avanços na terapêutica cardiovascular.

A despeito da grande aceitação, surgiram, então, algumas limitações ao método, sendo a reestenose a principal delas.

Três mecanismos principais foram então identificados como causa da reestenose: retração elástica do vaso, remodelamento negativo e hiperplasia intimal resultante do processo de reparação do tecido pós lesão da parede vascular. A reestenose limita a eficácia tardia da angioplastia em cerca de $40 \%$ dos casos. O uso

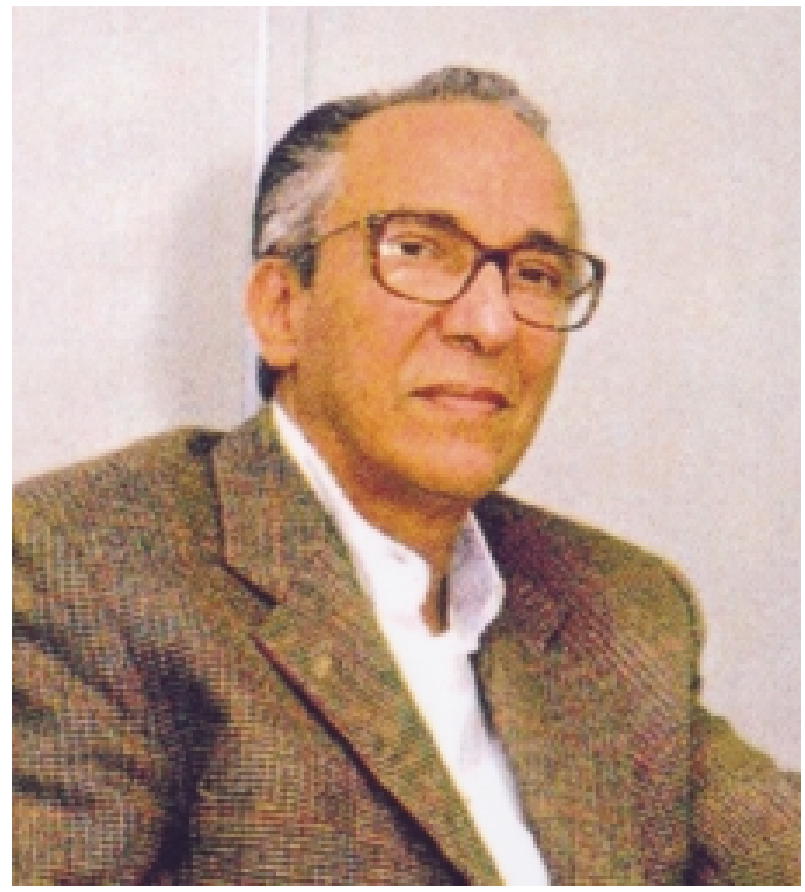

posterior dos stents reduziu as taxas de reestenose a $20 \%$, graças a dois mecanismos: eliminação da retração elástica e do remodelamento negativo. Entretanto os stents não tem ação sobre a hiperplasia intimal e o seu controle se constituiu no grande desafio da cardiologia na última década.

No afã de solucionar o problema numerosas técnicas mecânicas foram então propostas (ateromos, laser) inclusive testou-se um grande número de drogas: antiplaquetários, anti-lipemiantes, anti-inflamatórias, antitrombóticas, inibidores da ECA. Todas falharam a despeito de algumas delas terem apresentado boas respostas na redução da hiperplasia animal em estudos experimentais (ratos, coelhos, cão).

* Diretor do Instituto Dante Pazzanese de Cardiologia - São Paulo.

Professor Livre Docente da Universidade Federal de São Paulo (UNIFESP) - Escola Paulista de Medicina (EPM). 
Entretanto nos seres humanos nenhum efeito positivo foi observado.

Mais recentemente quatro pesquisadores dos Estados Unidos utilizando, na maioria das vezes, modelo de reestenose coronária no porco, mostraram que a rapamicina por via intra muscular reduzia a hiperplasia intimal após lesão vascular provocada pelo balão ${ }^{3-6}$. A rapamicina havia sido descoberta na Ilha de Páscoa no Chile na década de 60 e foi, na época considerada, como um antibiótico macrolítico e com ação antifúngica.

Somente após estes trabalhos experimentais mais recentes ela foi aceita como droga imunosupressora e antiproliferativa, o que levou o FDA americano a liberala, em 1999 para uso em pacientes pós transplante renal.

Tivemos a oportunidade de estudar, pela primeira vez, stents com eluição da rapamicina em seres humanos. No Instituto Dante Pazzanese em dezembro de 1999 tratamos trinta pacientes com obstrução coronária divididos em dois grupos: no primeiro, os stents tiveram liberação rápida intracoronária da droga (2 semanas); no segundo, liberação lenta (4 semanas).Os pacientes foram observados por um período de dois anos e a hiperplasia intimal foi avaliada pela angiografia coronária e ultra-som tri-dimensional intracoronário em todos, aos 4, 12 e 24 meses.

Esta investigação pioneira mostrou praticamente ausência de proliferação intimal nos pacientes, abrindose então nova era da cardiologia intervencionista, pelo controle da reestenose $\mathrm{e}^{7-10}$.

A despeito da grande importância e do apoio que os estudos experimentais proporcionaram ao desenvolvimento da cardiologia intervencionista menciono algumas das suas limitações: na maioria das vezes não houve correlação entre os resultados da experimentação animal e os observados na clínica: no caso da rapamicina no modelo animal a droga reduziu em 50\% a hiperplasia intimal e nos seres humanos praticamente eliminou-a; conclui-se portanto que não há um modelo de reestenose coronária no animal que reproduza as reações histológicas observadas no homem após intervenção mecânica ou farmacológica.

A despeito das numerosas contribuições da tecnologia experimental busca-se, ainda modelo de reestenose coronária no animal confiável e seguro que nos permita antever com segurança respostas imediatas e tardias de intervenções terapêuticas na circulação coronária humana.

\section{Referências}

1. Dotter CT, Judkins MP. Transluminal treatment of arteriosclerotic obstruction. Circulation 1964;30:654-69.

2. Grüntzig AR, Senning A, Siegenthaler WE. Nonoperative dilatation of coronary-artery stenosis: percutaneous transluminal coronary angioplasty. N Engl J Med 1979;301:61-8.

3. Gregory C, Huie P, Shorthouse R. Treatment with rapamycin blocks arterial intimal thickening following mechanical and alloimmune injury. Transplant Proc 1993;25:120-1.

4. Max SO, Jayaraman T, GO LO. Rapamycin-FKBP inhibits cell cycle regulators of proliferation in vascular smooth muscle cells. Circ Res 1995;76:412-7.

5. Poon M, Marx SO, Gallo R. Rapamycin inhibits vascular smoothmuscle cell migration. J Clin Invest 1996;98:2277-83.

6. Gallo R, Padurean A, Toschi V, Bichler J, Faloon JT, Chesebro JH, Fauster V, Badimon JJ. Prolonged thrombin inhibition reduces restenosis after balloon angioplasty in porcine coronary arteries. Circulation 1998;97:581-8.

7. Sousa JE, Costa MA, Abizaid A, Abizaid AC, Feres F, Pinto IMF, Seixas AC, Staico R, Mattos LA, Sousa AGMR, Falotico R, Jaeger J, Popma JJ, Serruys PW. Lack of neointimal proliferation after implantation of sirolimus-coatek stents in human coronary arteries: a quantitative coronary angiography and three-dimensional intravascular ultrasound study. Circulation 2001;103:192-5.

8. Sousa JE, Costa MA, Abizaid A, Rensing BJ, Abizaid AC, Tanajura LF, Kozuma K, Langenhove GV, Sousa AGMR, Falotico R, Jaeger J, Popma JJ, Serruys PW. Sustained supresion of neointimal proliferation by sirolimus-eluting stents: oneyear angiographic and intravascular ultrasound follow-up. Circulation 2001;104:2007-11.

9. Sousa JE, Costa MA, Sousa AGMR, Abizaid A, Seixas AC, Abizaid AC, Feres F, Mattos LA, Falotico R, Jeager J, Popma JJ, Serruys PW. Two-year angiographic and intravascular ultrasound follow-up implantation of sirolimus-eluting stents in human coronary arteries. Circulation 2003;107:381-3.

10. Sousa JE, Costa MA, Abizaid AC, Sousa AGMR, Feres F, Mattos LA, Centenero M, Maldonado G, Abizaid AC, Pinto IM, Falotico R, Jeager J, Popma JJ, Serruys PW. Sirolimus-eluting stent for the treatment of in-stent restenosis: a quantitative coronary and three-dimensional intravascular ultrasound study. Circulation 2003;107:24-7.

\section{Correspondência:}

J. Eduardo Sousa

Instituto Dante Pazzanese de Cardiologia

Av. Dr.Dante Pazzanese, 500/14 andar

04012-180 São Paulo - SP 